\title{
Optimization of Process Parameters for $\varepsilon$-Polylysine Production by Response Surface Methods
}

\author{
Maxiaoqi Zhu, ${ }^{1}$ Zhicai Zhang, ${ }^{1}$ Yiqiuyi Liu, ${ }^{1}$ Feng Wang, ${ }^{1}$ Lili Xia, \\ Jianwei Xia, ${ }^{2}$ and Hongming Guo ${ }^{2}$ \\ ${ }^{1}$ School of Food and Biological Engineering, Jiangsu University, Zhenjiang, Jiangsu 212013, China \\ ${ }^{2}$ Jiangsu Yiming Biological Co., Ltd., Taizhou, Jiangsu 223001, China
}

Correspondence should be addressed to Zhicai Zhang; zhangzhicai@ujs.edu.cn

Received 26 November 2015; Revised 15 April 2016; Accepted 9 May 2016

Academic Editor: Huining Xiao

Copyright (C) 2016 Maxiaoqi Zhu et al. This is an open access article distributed under the Creative Commons Attribution License, which permits unrestricted use, distribution, and reproduction in any medium, provided the original work is properly cited.

$\varepsilon$-Polylysine $(\varepsilon-\mathrm{PL})$ is a highly safe natural food preservative with a broad antimicrobial spectrum, excellent corrosion resistances, and great commercial potentials. In the present work, we evaluated the $\varepsilon$-PL adsorption performances of HZB-3B and D155 resins and optimized the adsorption and desorption conditions by single-factor test, response surface method, and orthogonal design. The complexes of resin and $\varepsilon$-PL were characterized by SEM and FITR. The results indicated that D155 resin had the best $\varepsilon$-PL adsorption performance and was selected for the separation and purification of $\varepsilon$-PL. The conditions for the static adsorption of $\varepsilon$-PL on D155 resin were optimized as follows: $\varepsilon$-PL solution $40 \mathrm{~g} / \mathrm{L}, \mathrm{pH} 8.5$, resins $15 \mathrm{~g} / \mathrm{L}$, and absorption time $14 \mathrm{~h}$. The adsorption efficiency of $\varepsilon$ $\mathrm{PL}$ under the optimal conditions was $96.84 \%$. The $\varepsilon$-PL adsorbed on the D155 resin was easily desorbed with $0.4 \mathrm{~mol} / \mathrm{L} \mathrm{HCl}$ at $30^{\circ} \mathrm{C}$ in $10 \mathrm{~h}$. The highest desorption efficiency was $97.57 \%$ and the overall recovery of $\varepsilon$-PL was $94.49 \%$ under the optimal conditions. The excellent $\varepsilon$-PL adsorption and desorption properties of D155 resin including high selectivity and adsorption capacity, easy desorption, and high stability make it a good candidate for the isolation of $\varepsilon$-PL from fermentation broths.

\section{Introduction}

Natural preservatives are promising food preservatives and have become a major research field worldwide in the recent years. $\varepsilon$-Polylysine $(\varepsilon-P L)$ is a polypeptide containing 25 to 30 lysine residues and usually synthesized with Streptomyces [1]. It is one of highly safe natural food preservatives with a broad antimicrobial spectrum, excellent corrosion resistances, and commercial potentials [2-4]. $\varepsilon$-PL can inhibit the growth of Gram-negative bacteria, yeast, and mold in the neutral and acidic environment, especially, for E. coli and Salmonella that cannot be effectively inhibited by other natural preservatives [5-8]. Therefore, it is highly valuable and has a very promising market prospect. Most researches have been focused on breeding high-yield $\varepsilon$-PL strains and optimizing fermentation process to improve $\varepsilon$-PL yields [9, $10]$. With the development of fermentation techniques, the extraction and purification of $\varepsilon$-PL in industrial production have become another research focus to lower production cost and improve product quality [11].
Ion exchange and ultra-filtration are two most widely used techniques for $\varepsilon$-PL separation [12]. Ion exchange technique has a great potential in isolation of active components from fermentation broth due to its short process, high recovery, and less pollution and has been extensively used in water treatment $[13,14]$ and extraction of active components from various media [14-18]. $\varepsilon$-PL is a cationic polymer at $\mathrm{pH}<\mathrm{pI}(9.0)$ and can be absorbed by cation exchange resin.

In the present work, the $\varepsilon$-PL adsorption performances and conditions of various ion exchange resins were evaluated by single-factor test. The adsorption conditions of $\varepsilon$-PL on the resins were optimized by response surface method. The desorption of $\varepsilon$-PL was optimized with the desorption efficiency by single-factor test and orthogonal array test. Based on the results, an optimum extraction process of $\varepsilon$-PL was proposed.

\section{Experimental}

2.1. Materials. $\mathrm{H}^{+}$resins HZD-5, HD-2, HZD-3B, D113, and D155 were provided by Shanghai Huazheng Technology Co., 
Ltd. (Shanghai, China), and were pretreated according to the manufacture's manual. All other reagents were of analytical grade. $\varepsilon$-PL was a gift from Yiming Biological Co. Ltd. (Jiangshu, China).

2.2. Determination of Adsorption and Desorption Efficiency. Based on the method reported by Itzhaki et al. [18], the adsorption amount, adsorption efficiency, and desorption efficiency were calculated as follows:

$$
\begin{aligned}
Q_{e} & =\frac{\left(C_{0}-C_{1}\right) V_{0}}{m}, \\
A_{r} & =\frac{C_{0}-C_{1}}{C_{0}} \times 100 \%, \\
D_{r} & =\frac{C_{2} V_{2}}{C_{0} V_{0}-C_{1} V_{1}} \times 100 \%=\frac{C_{2} V_{2}}{m Q_{e}} \times 100 \%, \\
Y & =A_{r} \times D_{r},
\end{aligned}
$$

where $C_{0}$ is the initial concentration of $\varepsilon$-PL $(\mathrm{g} / \mathrm{L}) ; C_{1}$ is the $\varepsilon$-PL concentration in the adsorption solution $(\mathrm{g} / \mathrm{L}) ; C_{2}$ is the $\varepsilon$-PL concentration in the eluent $(\mathrm{g} / \mathrm{L}) ; V_{0}$ is the volume of the initial $\varepsilon$-PL solution $(\mathrm{mL}) ; V_{1}$ is the volume of $\varepsilon$-PL solution after adsorption $(\mathrm{mL}) ; V_{2}$ is the volume of the eluent $(\mathrm{mL})$; $m$ is the weight of resin $(\mathrm{g}) ; Q_{e}$ is the absorbed amount of $\varepsilon$ $\mathrm{PL}(\mathrm{mg} / \mathrm{g}) ; A_{r}$ is adsorption efficiency; $D_{r}$ is the desorption efficiency; and $Y$ is the total recovery.

\subsection{Univariate Analysis of $\varepsilon-P L$ Adsorption}

2.3.1. Effects of $p H$ on $\varepsilon$-PL Adsorption. Five resins were pretreated and, respectively, divided into eight portions of $1 \mathrm{~g}$ resin. $\varepsilon$-PL solutions $(20 \mathrm{~mL} 40 \mathrm{~g} / \mathrm{L})$ with $\mathrm{pH}=2,3,4,5,6$, 7,8 , and 9 were added to the eight aliquots of each resin and allowed a $10 \mathrm{~h}$ adsorption at $25^{\circ} \mathrm{C}$ under stirring at $200 \mathrm{r} / \mathrm{min}$. The concentrations of $\varepsilon$-PL that remained in the solutions were then measured.

2.3.2. Effects of Resin Dosage on $\mathcal{\varepsilon}$-PL Adsorption. $\mathcal{E}$-PL solutions ( $20 \mathrm{~mL}, 40 \mathrm{~g} / \mathrm{L}, \mathrm{pH} 8.5$ ) were, respectively, added to $0.5 \mathrm{~g}, 1 \mathrm{~g}, 1.5 \mathrm{~g}$, and $2 \mathrm{~g}$ resins at $25^{\circ} \mathrm{C}$ and stirred at $200 \mathrm{r} / \mathrm{min}$ for $10 \mathrm{~h}$. The concentrations of $\varepsilon$-PL that remained in the solutions were then measured.

\subsubsection{Effects of Initial $\varepsilon-P L$ Concentration on $\varepsilon$-PL Adsorption.} Five portions of $1 \mathrm{~g}$ resins were, respectively, mixed with $20 \mathrm{~mL} 10 \mathrm{~g} / \mathrm{L}, 20 \mathrm{~g} / \mathrm{L}, 30 \mathrm{~g} / \mathrm{L}, 40 \mathrm{~g} / \mathrm{L}$, and $50 \mathrm{~g} / \mathrm{L} \varepsilon$-PL solutions $(\mathrm{pH} 8.5)$ at $25^{\circ} \mathrm{C}$ and stirred at $200 \mathrm{r} / \mathrm{min}$ for $10 \mathrm{~h}$. The concentrations of $\varepsilon$-PL that remained in the solutions were then measured.

2.3.4. Effects of Adsorption Time on $\varepsilon$-PL Adsorption. Fifteen portions of $1 \mathrm{~g}$ resins were, respectively, added to fifteen $20 \mathrm{~mL} 40 \mathrm{~g} / \mathrm{L} \varepsilon$-PL solutions $(\mathrm{pH}=8.5)$ at $25^{\circ} \mathrm{C}$ and stirred at $200 \mathrm{r} / \mathrm{min}$ for $1 \mathrm{~h}, 2 \mathrm{~h}, 3 \mathrm{~h}, 4 \mathrm{~h}, 5 \mathrm{~h}, 6 \mathrm{~h}, 7 \mathrm{~h}, 8 \mathrm{~h}, 9 \mathrm{~h}, 10 \mathrm{~h}$, $11 \mathrm{~h}, 12 \mathrm{~h}, 13 \mathrm{~h}, 14 \mathrm{~h}$, and $15 \mathrm{~h}$, respectively. The concentrations of $\varepsilon$-PL that remained in the solutions were then measured.
TABLE 1: Factors and levels of response surface design.

\begin{tabular}{lcccc}
\hline \multicolumn{5}{c}{ Factors } \\
Level & $\begin{array}{c}X_{1} \\
\text { Adsorption } \\
\mathrm{pH}\end{array}$ & $\begin{array}{c}X_{2} \\
\text { Resin amount } \\
(\mathrm{g} / \mathrm{L})\end{array}$ & $\begin{array}{c}X_{3} \\
\text { Initial } \\
\text { concentration } \\
(\mathrm{g} / \mathrm{L})\end{array}$ & $\begin{array}{c}X_{4} \\
\text { Adsorption } \\
\text { time }(\mathrm{h})\end{array}$ \\
\hline-1 & 8 & 5 & 20 & 10 \\
0 & 8.5 & 10 & 30 & 12 \\
1 & 9 & 15 & 40 & 14 \\
\hline
\end{tabular}

2.4. Response Surface Analysis of the Static $\varepsilon$-PL Adsorption. Based on the univariate analysis results, the effects of $\varepsilon$-PL concentration, initial $\mathrm{pH}$, resin dosage, and adsorption time on the $\varepsilon$-PL adsorption of HZD-3B and D155 resins were determined with 29 cycles of a response surface design of four factors and three levels using adsorption efficiency as the index. The regression analysis of the data was conducted with Design-Expert v8.0.6 software. The four factors and three levels of the response surface design of are shown in Table 1.

\subsection{Single-Factor Test of Static Desorption of $\varepsilon-P L$}

2.5.1. Effects of $\mathrm{HCl}$ Concentration. After being rinsed with three volumes of deionized water, ten portions of $\varepsilon$-PL adsorbed resins were, respectively, mixed with $20 \mathrm{~mL} 0$, $0.1,0.2,0.3,0.4,0.5,0.6,0.7,0.8,0.9$, and $1.0 \mathrm{~mol} / \mathrm{L} \mathrm{HCl}$ solutions at $25^{\circ} \mathrm{C}$ and stirred at $200 \mathrm{r} / \mathrm{min}$ for $6 \mathrm{~h}$. The $\varepsilon$-PL concentrations in the $\mathrm{HCl}$ solutions were measured.

2.5.2. Effects of Desorption Time. After being rinsed with three volumes of deionized water, $\varepsilon$-PL adsorbed resins were mixed with $20 \mathrm{~mL} 0.5 \mathrm{~mol} / \mathrm{L} \mathrm{HCl}$ solutions at $25^{\circ} \mathrm{C}$ and stirred at $200 \mathrm{r} / \mathrm{min}$ for $1 \mathrm{~h} \sim 12 \mathrm{~h}$. The $\varepsilon$-PL concentrations in the $\mathrm{HCl}$ solutions were measured.

2.5.3. Effects of Desorption Temperature. After being rinsed with three volumes of deionized water, the $\varepsilon$-PL adsorbed resins were mixed with $20 \mathrm{~mL} 0.5 \mathrm{~mol} / \mathrm{L} \mathrm{HCl}$ solutions at $15^{\circ} \mathrm{C}, 20^{\circ} \mathrm{C}, 25^{\circ} \mathrm{C}, 30^{\circ} \mathrm{C}, 35^{\circ} \mathrm{C}$, and $40^{\circ} \mathrm{C}$, respectively, and stirred at $200 \mathrm{r} / \mathrm{min}$ for $6 \mathrm{~h}$. The $\varepsilon$-PL concentrations in the $\mathrm{HCl}$ solutions were then measured.

2.6. Orthogonal Array Test of the Static Desorption of $\varepsilon$-PL. Based on the single-factor test results, the effects of $\mathrm{HCl}$ concentration, desorption time, and desorption temperature on the desorption efficiency of $\varepsilon$-PL from HZD-3B and D155 resins were evaluated by the orthogonal array test with three factors and three levels. The factors and levels for $L_{9}\left(3^{3}\right)$ orthogonal test of the resins are shown in Table 2.

2.7. Data Analysis. All tests were repeated three times and the mean \pm SD values were reported. $t$-test was used to determine the statistical significance. $p<0.05$ was considered as statistical significance.

2.8. Apparatus. Fourier Transform Infrared Spectroscopy (FTIR) was performed on a Thermo-Fisher Nicolet FT-IR 
TABLE 2: Factors and levels in $L_{9}\left(3^{4}\right)$ orthogonal array test for HZD$3 \mathrm{~B}$ and D155 resins.

\begin{tabular}{|c|c|c|c|c|c|c|c|}
\hline & \multirow{2}{*}{ Level } & \multicolumn{3}{|c|}{ HZD-3B } & \multicolumn{3}{|c|}{ D155 } \\
\hline & & 1 & 2 & 3 & 1 & 2 & 3 \\
\hline \multirow{3}{*}{ Factor } & A: $\mathrm{HCl}$ concentration $(\mathrm{mol} / \mathrm{L})$ & 0.3 & 0.4 & 0.5 & 0.2 & 0.3 & 0.4 \\
\hline & $B$ : desorption time $(\mathrm{h})$ & 8 & 9 & 10 & 8 & 9 & 10 \\
\hline & $C$ : desorption temperature $\left({ }^{\circ} \mathrm{C}\right)$ & 20 & 25 & 30 & 20 & 25 & 30 \\
\hline
\end{tabular}

spectrometer (USA) in the region of $650-4,000 \mathrm{~cm}^{-1}$ at a resolution of $4 \mathrm{~cm}^{-1}$. The morphologies of the resins with and without $\varepsilon$-PL adsorbed were imaged with a Hitachi S-4800 microscope (Japan).

\section{Results and Discussion}

3.1. Optimization of Static Adsorption of $\mathcal{E}$-PL by Single-Factor Test. Ion exchange resins have been widely applied for the high efficiency extraction of bioproducts, especially proteins and polypeptides, from fermentation broth in the form of chromatography [19]. Ion exchange resins can be divided into two types: cation and anion exchange resins. Based on their acidities, cation resins can be classified into strong acid and weak acid cation exchange resins. $\varepsilon$-PL is a weak alkaline homopolymer composed of 25-30 L-lysine residues linked by the peptide bond between carboxyl and $\varepsilon$-amino groups of Llysine [19-22] and carries a number of positive charges in a specific $\mathrm{pH}$ range. Therefore, in the present work, five cation exchange resins were selected to isolate $\varepsilon$-PL from the fermentation broth of Streptomyces sp. Ion exchange chromatography is usually conducted with fixed-bed columns. However, $\varepsilon$-PL aqueous solution has a high viscosity due to the unique structure of $\varepsilon$-PL, which causes long isolation process with fixed-bed columns. Therefore, dynamic adsorption separation is suitable to $\varepsilon$-PL. In the present work, the batch static adsorption and desorption were conducted to evaluate the $\varepsilon$ $\mathrm{PL}$ adsorption and desorption properties of the ion exchange resins.

3.1.1. Effects of $p H$. $\varepsilon$-PL is amphoteric and has an isoelectric point (IP) at $\sim 9.0$ [23]. Therefore, $\mathrm{pH}$ can affect $\varepsilon$-PL adsorption affinity on resins by alternating the ionization of $\mathcal{E}$-PL [24]. $\varepsilon$-PL is polyvalent cation at $\mathrm{pH}$ lower than 9.0 and is decomposed at $\mathrm{pH}$ higher than $9[25,26]$. Therefore, the adsorption of $\varepsilon$-PL on resins in the $\mathrm{pH}$ range of $2 \sim 9$ was investigated. Figure 1(a) shows the increases in the adsorption efficiencies of $\varepsilon$-PL on all five resins with the increase of $\mathrm{pH}$ in the test range, consistent with the conclusion reported by Zhang et al. [27]. The highest $\varepsilon$-PL adsorption efficiencies of five resins were obtained at $\mathrm{pH} 9$ with values of $41.58 \%$ for resin D113, 57.48\% for resin HZD-5, 69.55\% for resin HD-2, $78.60 \%$ for D155 resin, and $84.71 \%$ for HZD-3B resin. HZD$3 \mathrm{~B}$ and D155 showed higher $\varepsilon$-PL adsorption capacities and D113 had the lowest $\varepsilon$-PL adsorption capacity.

3.1.2. Effects of Resin Dosage. The effects of resin dosage on the $\varepsilon$-PL adsorption efficiency are illustrated in Figure 1(b). As can be seen, the $\varepsilon$-PL adsorption efficiencies of all resins increased with the increase of resin dosage. It can be explained that more resins provided more exchangeable sites for $\varepsilon$-PL, resulting in higher adsorption efficiency. The $\varepsilon$ PL adsorption efficiencies of HZD-3B and D155 resins were dramatically increased as the resin dosage increased from $2.5 \mathrm{~g} / \mathrm{L}$ to $7.5 \mathrm{~g} / \mathrm{L}$ and slightly increased with the increase of resin dosage from $7.5 \mathrm{~g} / \mathrm{L}$ to $10 \mathrm{~g} / \mathrm{L}$. The $\varepsilon$-PL adsorption efficiencies of other three resins were gradually increased with the increase of the absorbent dosage. The highest adsorption efficiencies were found in $10 \mathrm{~g} / \mathrm{L}$ D155 and HZD-3B resins with values of $92.63 \%$ and $95.23 \%$, respectively.

3.1.3. Effects of Initial $\varepsilon$-PL Concentration. As shown in Figure 1(c), the $\varepsilon$-PL adsorption efficiency of the resins rapidly increased as the initial $\varepsilon$-PL concentration increased from $10 \mathrm{~g} / \mathrm{L}$ to $20 \mathrm{~g} / \mathrm{L}$. It can be explained that large amounts of $\varepsilon$ $\mathrm{PL}$ at high concentrations rapidly adsorbed on the resins and consequently saturated the resins. As the $\varepsilon$-PL concentration further increased from $20 \mathrm{~g} / \mathrm{L}$ to $40 \mathrm{~g} / \mathrm{L}$, the adsorption efficiency was gradually increased and the maximum adsorption capacity of the resins was reached. Further increasing initial $\varepsilon$-PL concentration from $40 \mathrm{~g} / \mathrm{L}$ to $50 \mathrm{~g} / \mathrm{L}$ led to a slight decline in the $\varepsilon$-PL adsorption efficiency. The $\varepsilon$-PL adsorption efficiencies of all five resins were obtained in $40 \mathrm{~g} / \mathrm{L} \varepsilon$-PL solution with values of $33.27 \%$ for D113 resin, $59.77 \%$ for HZD-5 resin, $67.77 \%$ for $\mathrm{HD}-2$ resin, $81.7 \%$ for $\mathrm{D} 155$ resin, and $83.98 \%$ for $\mathrm{HZD}-3 \mathrm{~B}$ resin. Therefore, initial $\varepsilon$-PL concentration was optimized as $40 \mathrm{~g} / \mathrm{L}$. In addition, both HZD-3B and D155 resins showed higher $\varepsilon$-PL adsorption capacities and D113 resin had the lowest $\varepsilon$-PL adsorption capacity under the optimized conditions.

3.1.4. Effects of Adsorption Time. Based on their locations in resins, the adsorption sites are classified into two types: the sites on the surfaces of the resins and the sites in intraresin. The adsorption rates of these two types of sites are different. The adsorbate is rapidly absorbed by the sites on resin surface. In contrast, the adsorbate needs to diffuse into the intraparticle of the resins before being absorbed by the sites in the intraresin [28]. The diffusion to the intraparticle is a slow adsorption process subjected to fast adsorption stage, slow adsorption stage, and equilibrium stage [29-31]. As shown in Figure $1(\mathrm{~d})$ for the $\varepsilon$-PL adsorption efficiency-time curves of the resins (Figure $1(\mathrm{~d})$ ), the $\varepsilon$-PL adsorption on all five resins was subjected to three stages with the extension of adsorption time as described above. At the first stage $(0-7 \mathrm{~h}), \varepsilon$-PL rapidly adsorbed on the resins and the adsorption efficiency linearly increased with the adsorption time. At this stage, the ion exchange adsorption occurred between $\varepsilon$-PL molecules and the ion exchange sites on the surface of resins. The adsorption became slower at the second stage from $7 \mathrm{~h}$ to $12 \mathrm{~h}$. During this stage, $\varepsilon$-PL diffused into the interior of resins, adsorbed on the ion exchange sites within the resins and retained in the interior of the resin. Thereafter, during the third stage (after $12 \mathrm{~h}$ ), the adsorption reached an equilibrium. All ion exchange sites in the resin were saturated and no ion exchange adsorption occurred. The highest adsorption efficiencies on the resins were reached at $12 \mathrm{~h}$ with values of $40.46 \%$ for D113 resin, $61.94 \%$ for $\mathrm{HZD}-5$ resin, $73 \%$ for $\mathrm{HD}-2$ resin, $87.67 \%$ for 


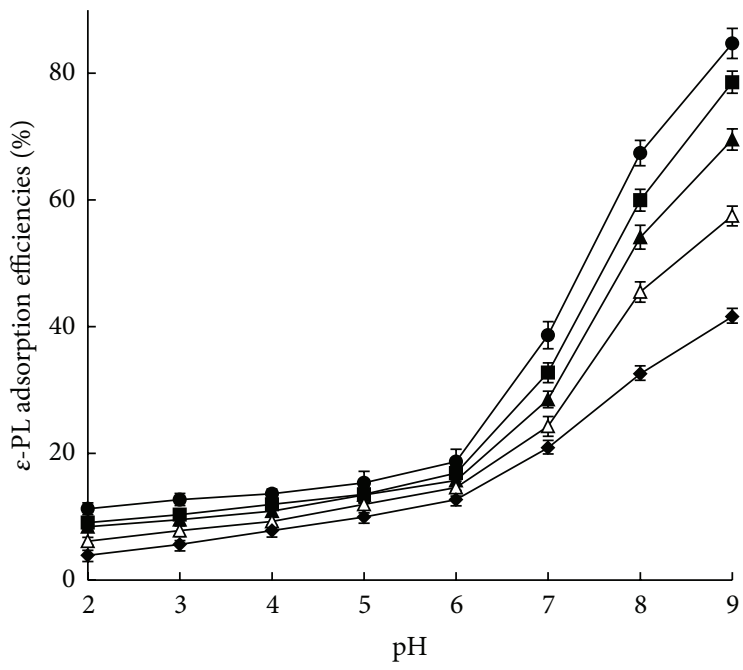

(a)

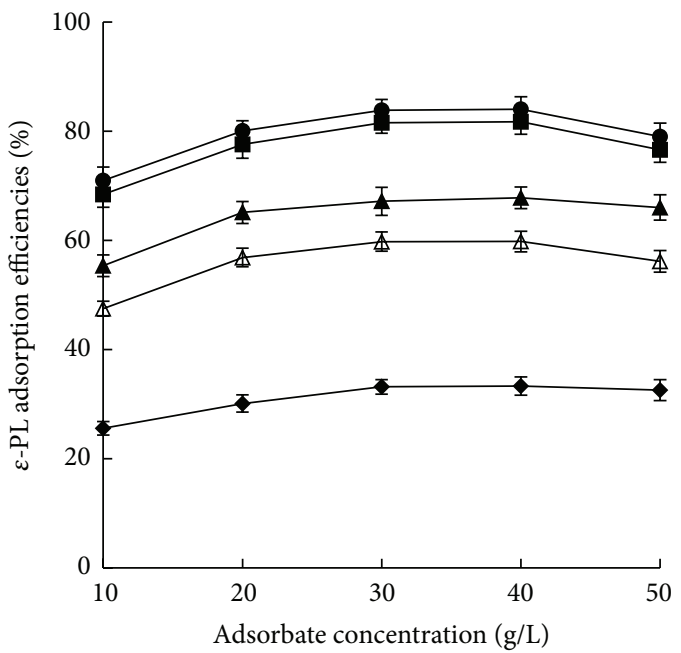

(c)

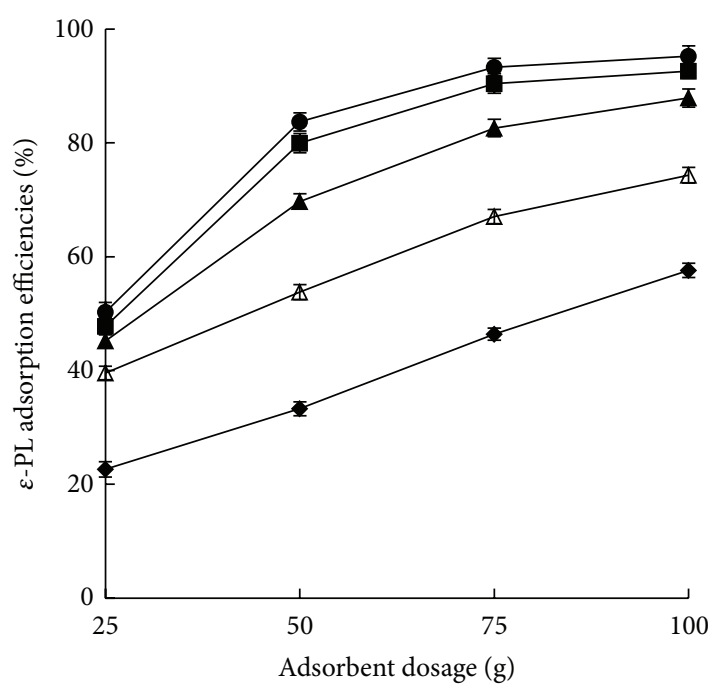

(b)

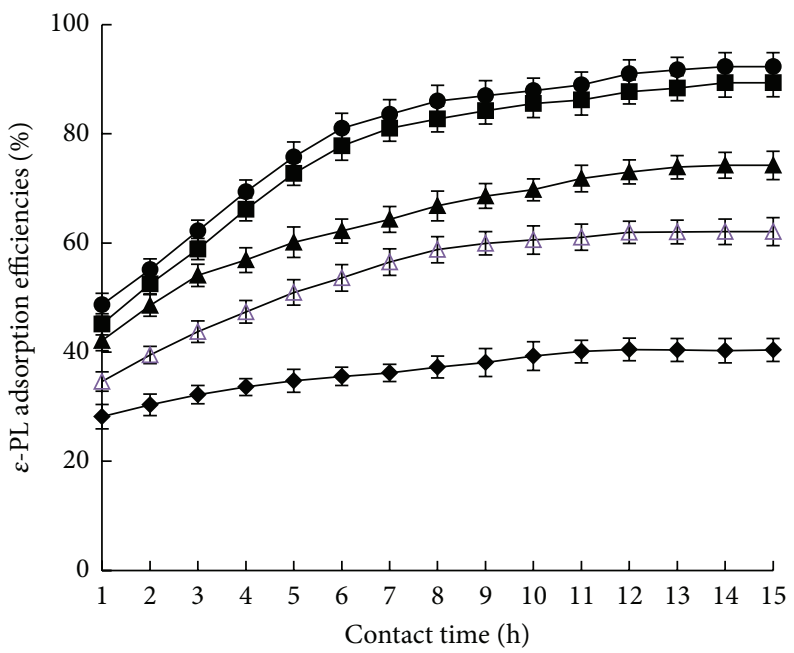

(d)

FIGURE 1: Effects of $\mathrm{pH}(\mathrm{a})$, adsorbent dosage (b), adsorbate concentration, (c) and contact time (d) on the $\varepsilon$-PL adsorption efficiencies of HZD3B $(\bullet)$, D155 $(\bullet)$, HD-2 $(\boldsymbol{\bullet})$, HZD-5 $(\triangle)$, and D113 $(\bullet)$ resins.

D155 resin, and 90.99\% for HZD-3B resin. Similarly, HZD$3 \mathrm{~B}$ and D155 resins showed higher $\varepsilon$-PL adsorption capacities and D113 resin showed lowest adsorption capacity under the testing conditions.

In all, the single-factor tests indicate that all five resins can absorb $\varepsilon$-PL with different adsorption capacities. HZD$3 \mathrm{~B}$ and D155 resins had higher $\varepsilon$-PL adsorption capacities, followed by HD-2 and HZD-5 resins. D113 resin showed lowest adsorption capacity. Therefore, HZD-3B and D155 resins were selected to further optimize the $\varepsilon$-PL adsorption conditions by response surface method in the following experiments.

3.2. Optimization of the Static Adsorption of $\varepsilon$-PL by Response Surface Method. Based on single-factor tests of the $\varepsilon$-PL adsorption of HZD-3B and D155 resins, $\mathrm{pH}$, resin dosage, initial concentration of $\varepsilon$-PL solution, and adsorption time were selected as independent variables and the adsorption efficiency was used as an dependent variable to further optimize the $\varepsilon$-PL adsorption conditions using Box-Behnken design principle with four factors, three levels, and a total of 29 experiments. Three levels were coded as $-1,0$, and +1 , respectively [32]. The experimental design and results are shown in Table S1 (see Supplementary Material available online at http://dx.doi.org/10.1155/2016/3785036). The variance analysis of the data was conducted in Design-Expert v8.0.6 software (Table S2).

Regression analysis of the test results was conducted in Design-Expert v8.0.6 software. The fitting quadratic polynomial regression equations are as follows.

For HZD-3B resin,

$$
\begin{aligned}
Y= & 93.15+1.99 X_{1}+3.89 X_{2}+2.03 X_{3}+9.09 X_{4} \\
& +3.21 X_{2} X_{3}-3.05 X_{2}^{2}-8.51 X_{4}^{2} .
\end{aligned}
$$


For D155 resin,

$$
\begin{aligned}
Y= & 93.43+4.05 X_{2}-3.25 X_{1} X_{2}+6.26 X_{2} X_{3} \\
& -4.44 X_{2}^{2}-3.01 X_{3}^{2},
\end{aligned}
$$

where $Y$ is the index value (adsorption efficiency) and $X_{1}, X_{2}$, $X_{3}$, and $X_{4}$ represent $\mathrm{pH}$, resin dosage, initial concentration, and adsorption time, respectively.

The $R^{2}$ values of the modeling analysis of HZD-3B and D155 resins are 0.9390 and 0.8914 , respectively, indicating that the model can fit experimental data well. The high coefficient of determination also suggests a strong correlation between the experimental values and the predicted values in the two models [33]. The regression equation can be used to optimize four parameters in the adsorption process of $\varepsilon$-PL. Both models showed the lack-of-fit $p>0.05$, indicating that the regression equation was highly reliable and credible and the experimental error could be negligible. Therefore, the two models can be used to determine the relationship between the independent variables and dependent variables [34]. The quadratic regression equation was able to precisely predict the theoretical value of dependent variable, indicating that the model successfully analyzed and optimized the experimental results.

3.3. Variance Analysis of the $\varepsilon$-PL Adsorption on HZD-3B Resin by Response Surface Method. Both resin dosage and initial $\varepsilon$-PL concentration significantly affected the adsorption of $\varepsilon$-PL on HZD-3B resin (Table S2). The effects of resin dosage-pH and initial $\varepsilon$-PL concentration-resin dosage on the $\varepsilon$-PL adsorption of D155 resin reached significant and extremely significant levels, respectively. The response surface plots of the interactions between various factors on the dependent variable ( $\varepsilon$-PL adsorption efficiency) were determined and Figure 2 shows the response surface plots of the factors that significantly affected $\varepsilon$-PL adsorption. Steep surfaces indicate more significant effects and flat surfaces represent weaker effects of the factors. Denser contours indicate greater impacts of the factors on the $\varepsilon$-PL adsorption efficiency and vice versa. The contour shape reflects the strength of the interaction between two factors. The circular contours represent weak interactions and less significant effects and oval contours indicate strong interactions and more significant effects.

Based on these results the following can be concluded. (1) The $\varepsilon$-PL adsorption conditions of HZD-3B resin were determined by the response surface method as initial $\varepsilon$ $\mathrm{PL}$ concentration $40 \mathrm{~g} / \mathrm{L}$, resin dosage $15 \mathrm{~g} / \mathrm{L}, \mathrm{pH} 8.65$, and adsorption time $12.8 \mathrm{~h}$. The $\varepsilon$-PL adsorption efficiency could reach $99.49 \%$ under the optimal conditions. Considering the practical operation process, we proposed the practical optimum adsorption conditions as initial $\varepsilon$-PL concentration $40 \mathrm{~g} / \mathrm{L}$, resin dosage $15 \mathrm{~g} / \mathrm{L}, \mathrm{pH} 8.5$, and adsorption time $13 \mathrm{~h}$. The experimental $\varepsilon$-PL adsorption efficiency was $97.69 \%$ under the proposed conditions, consistent with the response surface results. (2) The optimal $\varepsilon$-PL adsorption conditions of
D155 resin were determined by the response surface method as initial $\varepsilon$-PL concentration $37.94 \mathrm{~g} / \mathrm{L}$, resin dosage $2.85 \mathrm{~g} / \mathrm{L}$, $\mathrm{pH} 8.04$, and adsorption time $13.76 \mathrm{~h}$. The $\varepsilon$-PL adsorption efficiency can reach $99.48 \%$. The corrected practical adsorption operation conditions are initial $\varepsilon$-PL concentration $40 \mathrm{~g} / \mathrm{L}$, resin dosage $3.0 \mathrm{~g}, \mathrm{pH} 8$, and adsorption time $14 \mathrm{~h}$. The experimental $\varepsilon$-PL adsorption efficiency under the optimal operation conditions was $96.84 \%$, consistent with the response surface analysis result. These results indicate the model is reliable.

3.4. Morphologies of D155 and HZD-3B Resins. Figure 3 shows the SEM images of D155 and HZD-3B resins before and after $\varepsilon$-PL adsorbed. Both resins displayed a plicate and porous surface structure. D155 resin possessed large, deep, and sparse pores with a nearly network structure, while HZD$3 \mathrm{~B}$ resin contained small, shallow, and dense pores (Figures $3(a)$ and $3(c)$ ). Their porous structure provided more adsorption sites and increased the contact area and diffusion of $\varepsilon$-PL in the resins during the adsorption. The SEM images of the resins after the adsorption indicated that the $\varepsilon$-PL molecules were trapped and adsorbed into the pores and surfaces of resins (Figures 3(b) and 3(d)). The $\varepsilon$-PL layer adsorbed on $\mathrm{f}$ D155 resin surface was uniform and thin and that adsorbed on the surface of HZD-3B resin surface was dense and thick.

3.5. Infrared Spectra Analysis before and after $\varepsilon$-PL Adsorption. $\varepsilon$-PL is a polyamide compound and can be easily identified by its characteristic IR absorption peaks. As can be seen from Figure 4, both resins showed similar characteristic IR spectra after the $\varepsilon$-PL adsorption. The characteristic absorption bands at $\sim 1674.3 \mathrm{~cm}^{-1}$ were attributed to the stretching vibration band of $\mathrm{C}=\mathrm{O}$ in amide groups (amide absorption band I). The absorption peak at $1570.1 \mathrm{~cm}^{-1}$ was assigned to bending variation of - $\mathrm{NH}$ group and stretching vibration of -CN group (amide absorption band II). These two amide absorption bands confirmed the existence of amide groups. The absorption bands at $3270 \mathrm{~cm}^{-1}$ and $3099 \mathrm{~cm}^{-1}$ were attributed to the Fermi resonance generated from the frequency multiplication of the amide absorption band II and the stretching vibration of $-\mathrm{NH}$ group, respectively. The peaks at $3431.3 \mathrm{~cm}^{-1}$ and $2944.6 \mathrm{~cm}^{-1}$ were ascribed to the asymmetric stretching of $-\mathrm{NH}_{2}$ group and stretching of saturate $\mathrm{C}-\mathrm{H}$ bond, respectively. The peaks at $1461.5 \mathrm{~cm}^{-1}$ and $1436.4 \mathrm{~cm}^{-1}$ were due to $\mathrm{CH}_{2}$ groups. These results suggest that $\varepsilon$-PL was absorbed on the resin.

3.6. Optimization of Static Desorption of $\varepsilon$-PL by Single-Factor Test. The $\varepsilon$-PL adsorbed on the resin can be desorbed with $\mathrm{NaOH}, \mathrm{NH}_{4} \mathrm{OH}$, sodium salt, ammonium salt, and acids. However, the pHs of both $\mathrm{NaOH}$ and $\mathrm{NH}_{4} \mathrm{OH}$ eluents are higher than 9.0, which can cause the degradation of $\varepsilon$ PL $[25,26]$. In addition, the high concentrations of salts in the eluents need to be removed to obtain high purity of $\varepsilon$-PL. Acids, especially $\mathrm{HCl}$, for $\varepsilon$-PL desorption, can avoid the decomposition of $\varepsilon$-PL and be removed simply by evaporation under reduced pressure. Therefore, $\mathrm{HCl}$ was used to desorb $\varepsilon$-PL from the resins in the present work. 


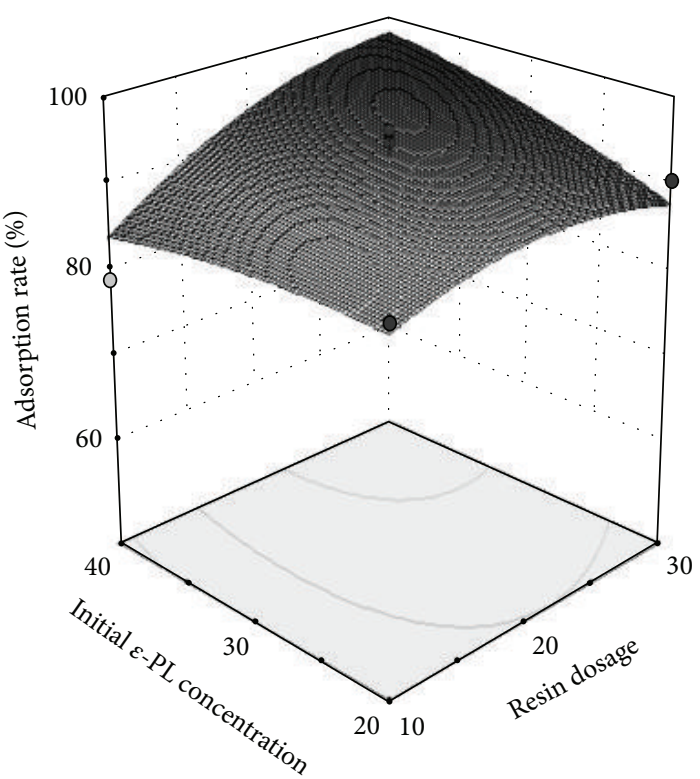

(a)

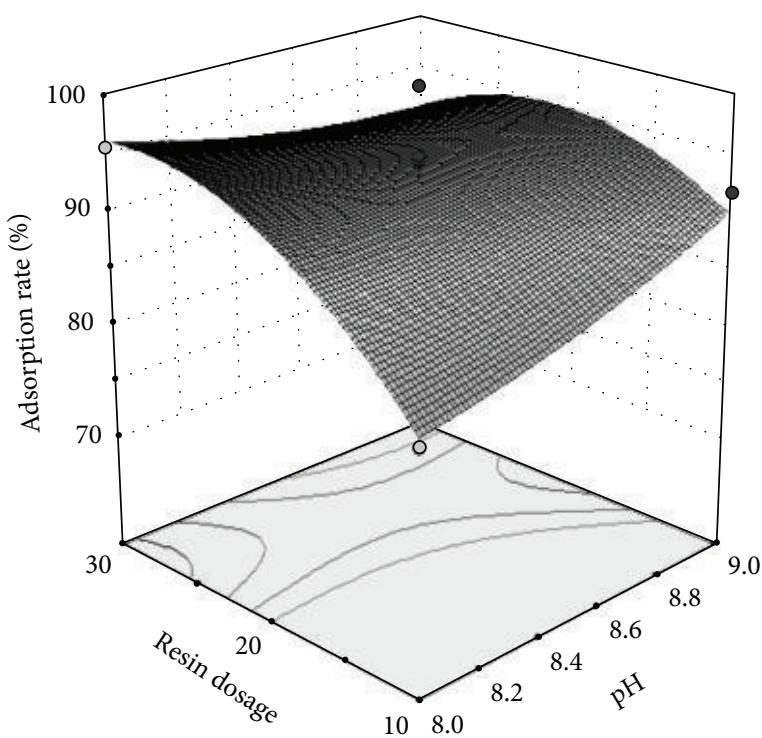

(b)

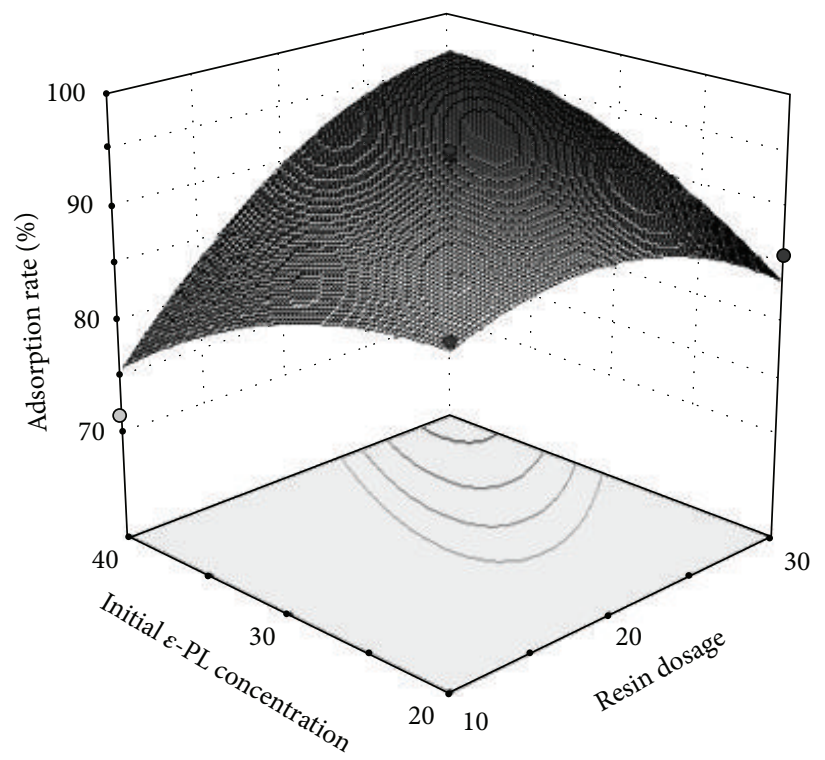

(c)

FIGURE 2: Response surface plots for the effects of interactions between variables on the adsorption efficiency. (a) Initial $\varepsilon$-PL concentration and resin dosage, HZD-3 resin; (b) resin dosage and pH, D155 resin; (c) initial $\varepsilon$-PL concentration and resin dosage, D155 resin.

3.6.1. Effects of $\mathrm{HCl}$ Concentration. The $\varepsilon$-PL desorption from resins by $\mathrm{HCl}$ follows the ion exchange equation:

$$
\mathrm{H}^{+}+\varepsilon \text {-PL-resin } \Longleftrightarrow \varepsilon \text {-PL }{ }^{+}+\mathrm{H} \text {-resin }
$$

Therefore, high concentration of $\mathrm{HCl}$ is in favor of the $\varepsilon$-PL desorption. However, excessive $\mathrm{HCl}$ can increase the production cost and corrode equipment. Hence, the $\mathrm{HCl}$ concentration for the $\varepsilon$-PL desorption was first optimized. The $\varepsilon$-PL desorption was conducted in $\mathrm{HCl}$ solutions at concentrations ranging from 0.1 to $1.0 \mathrm{~mol} / \mathrm{L}$ at $25^{\circ} \mathrm{C}$ for $6 \mathrm{~h}$. As shown in Figures 5(a) and 5(b), the $\varepsilon$-PL desorption efficiency increased with the increase of $\mathrm{HCl}$ concentration and peaked at $\mathrm{HCl}$ concentration of $0.4 \mathrm{~mol} / \mathrm{L}$ with values of $83.67 \%$ for rHZD-3B resin and $92.88 \%$ for D155 resin. Further increasing $\mathrm{HCl}$ concentration led to a decline in desorption efficiency. Therefore, $0.4 \mathrm{~mol} / \mathrm{L} \mathrm{HCl}$ was used for $\varepsilon$-PL desorption from the resins.

3.6.2. Effects of Desorption Time. The $\varepsilon$-PL desorption from the resins was conducted in $0.5 \mathrm{~mol} / \mathrm{L} \mathrm{HCl}$ at $25^{\circ} \mathrm{C}$ for various periods of time. As shown in Figures 5(c) and 5(d), the $\varepsilon$-PL desorption efficiencies of HZD-3B and D155 resins increased from $1 \mathrm{~h}$ to $8 \mathrm{~h}$ and reached $62.48 \%$ and $83.86 \%$, respectively. 


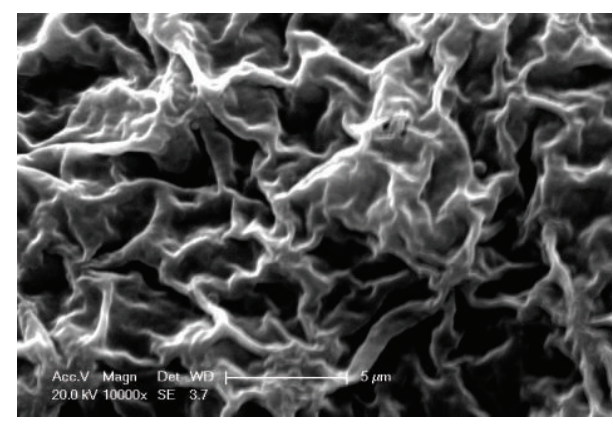

(a)

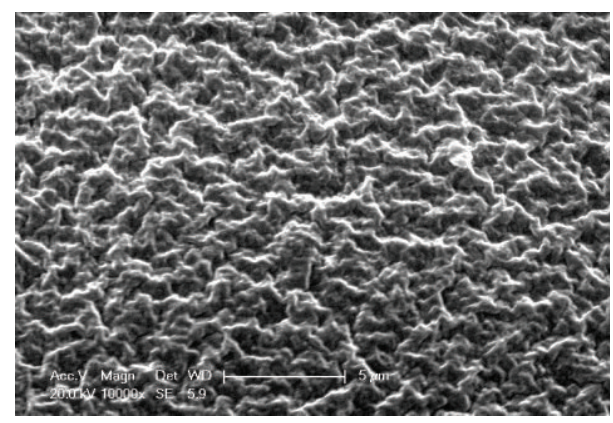

(c)

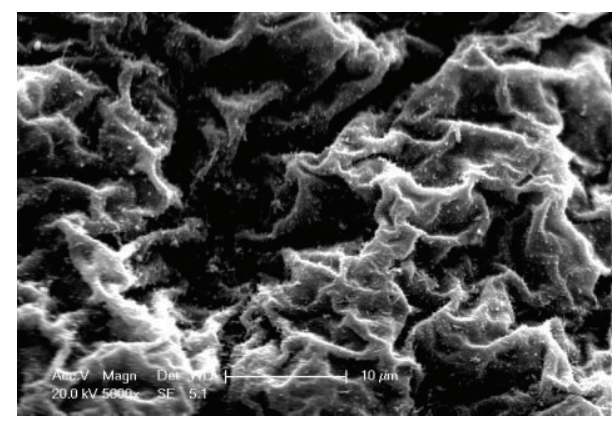

(b)

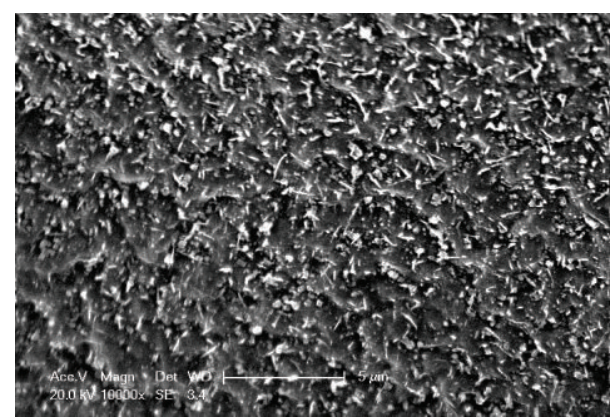

(d)

FIGURE 3: SEM images of resins before and after $\varepsilon$-PL adsorption. (a) D155, before adsorption; (b) D155, after adsorption; (c) HZD-3B, before adsorption; (d) HZD-3B, after adsorption.

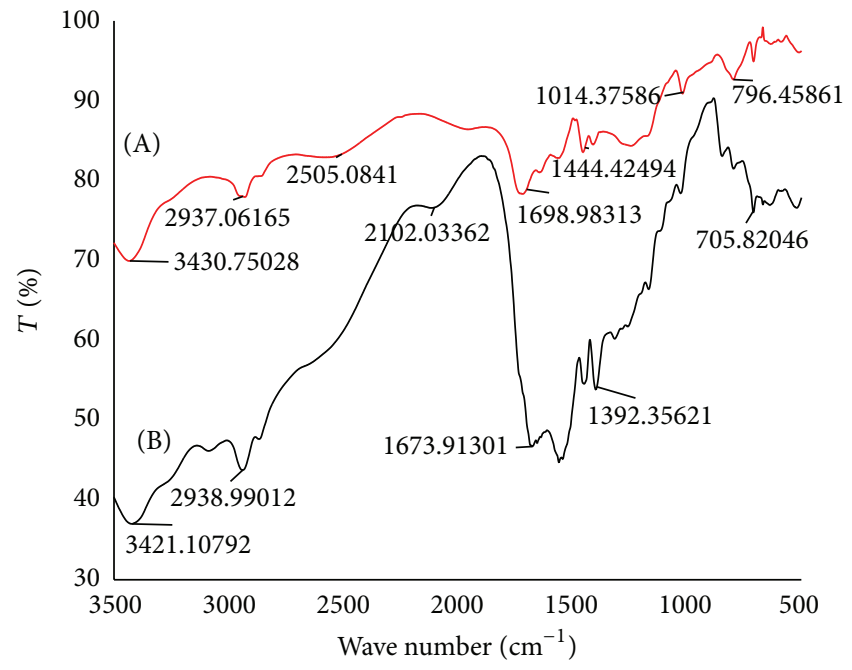

- (A) Before adsorption

- (B) After adsorption

(a)

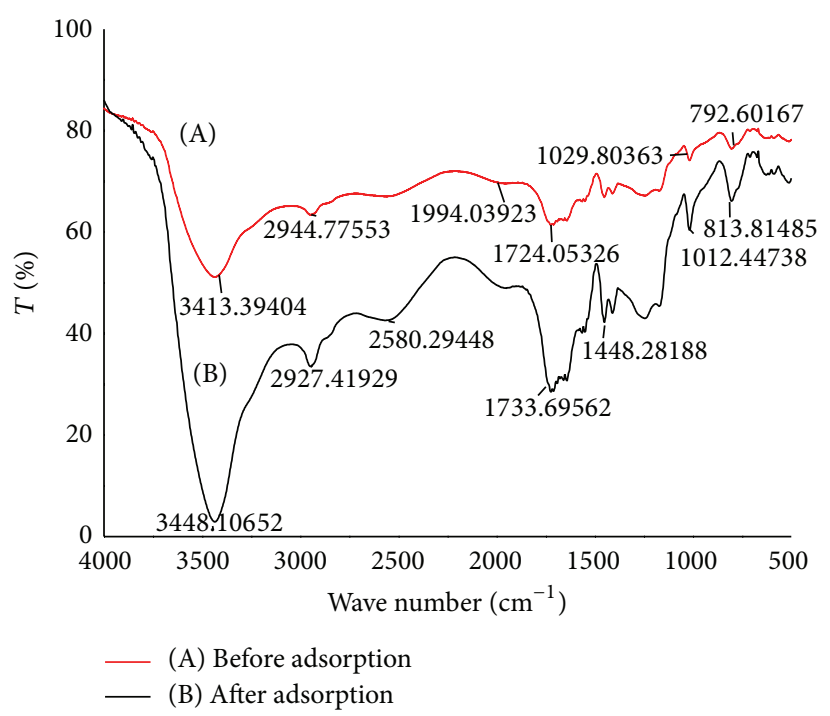

(b)

FIgURE 4: IR spectra of D155 (a) and HZD-3B (b) resins before and after $\varepsilon$-PL adsorption.

Further extending desorption time showed no significant effect on the $\varepsilon$-PL desorption efficiency. The desorption time was then optimized as $8 \mathrm{~h}$.

3.6.3. Effects of Desorption Temperature. It has been reported that temperature can significantly influence the equilibrium reaction of ion exchange [35]. The $\varepsilon$-PL desorption was conducted in $0.5 \mathrm{~mol} / \mathrm{L} \mathrm{HCL}$ at various temperatures for $6 \mathrm{~h}$. No significant effects of temperature on the $\varepsilon$-PL desorption were observed (Figures 5(e) and 5(f)). The desorption efficiencies of both HZD-3B and D155 resins increased slightly as the temperature increased from $15^{\circ} \mathrm{C}$ to $30^{\circ} \mathrm{C}$ and reached 


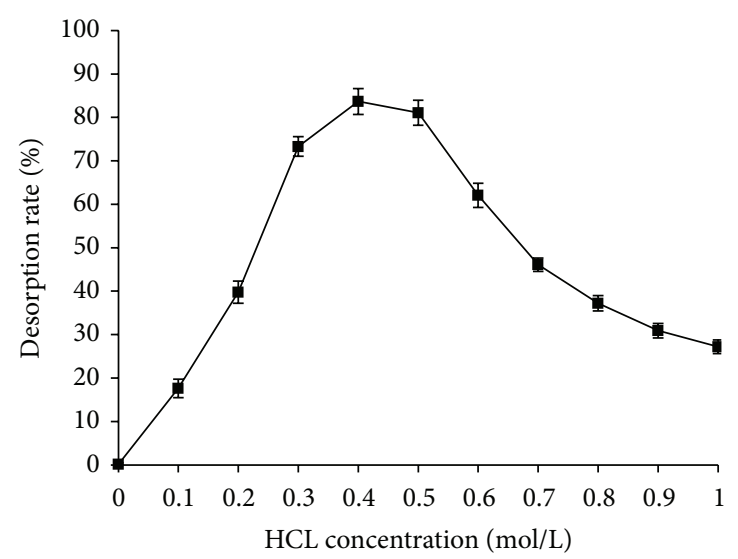

(a)

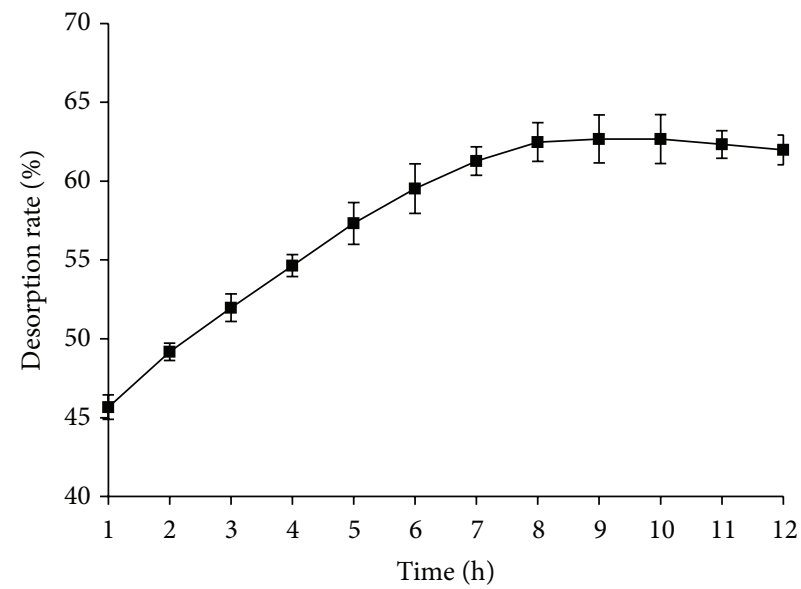

(c)

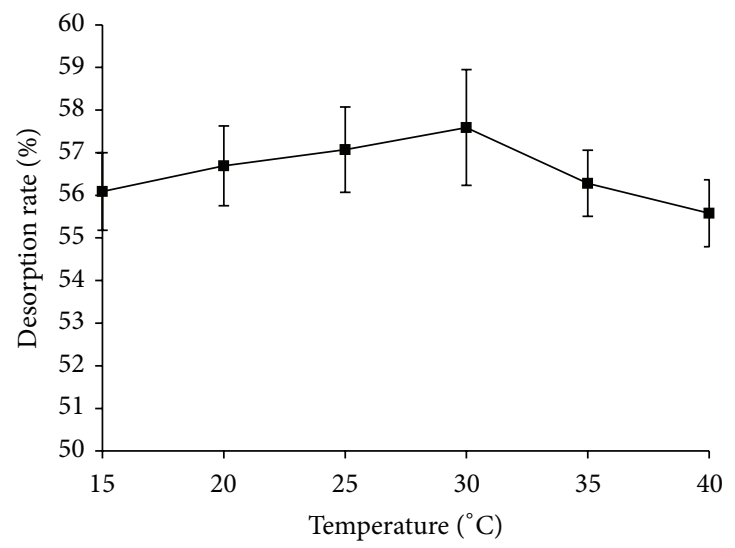

(e)

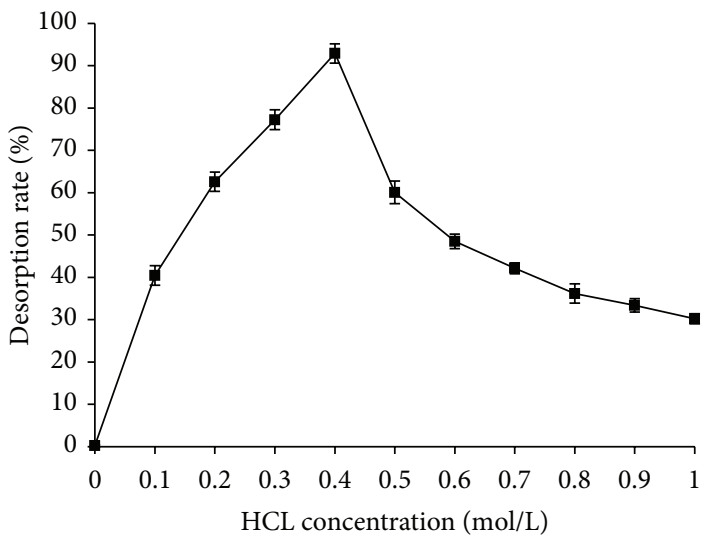

(b)

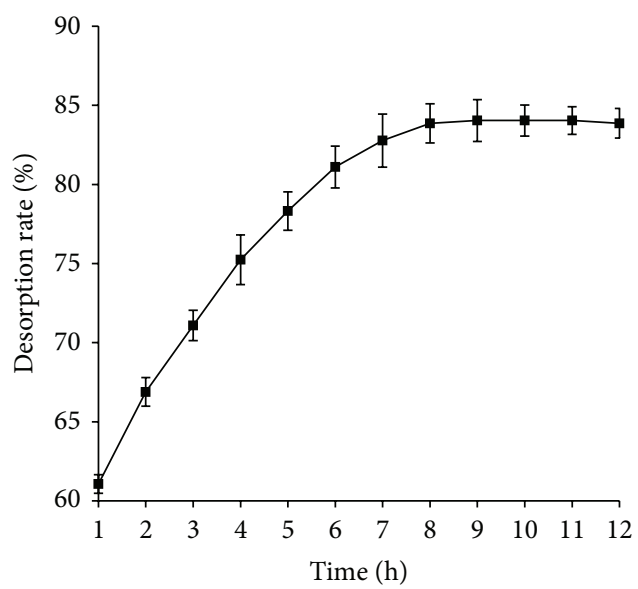

(d)

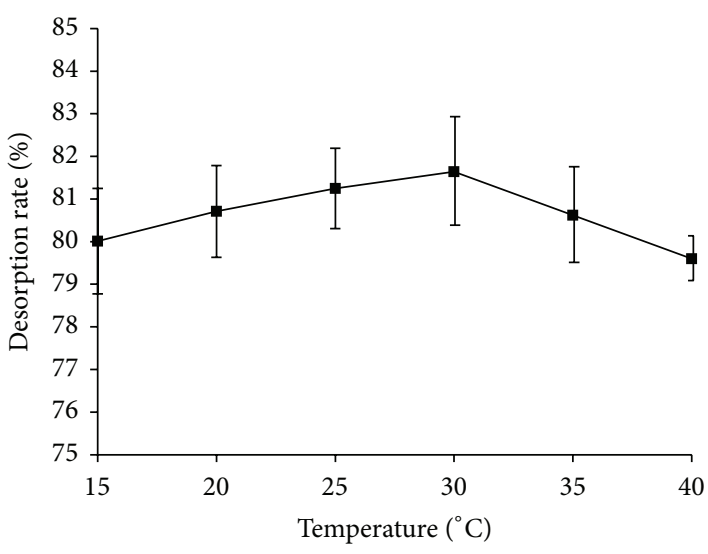

(f)

FIGURE 5: Effects of desorption factors on the $\varepsilon$-PL desorption efficiencies of HZD-3B and D155 resins. (a) HCl concentration for HZD3B resin; (b) $\mathrm{HCl}$ concentration for D155 resin; (c) desorption time for HZD-3B resin; (d) desorption time for D155 resin; (e) desorption temperature for HZD-3B resin; (f) desorption temperature for D155 resin.

$81.64 \%$ and $57.59 \%$, at $30^{\circ} \mathrm{C}$, respectively. Further increasing desorption temperature led to a slight decrease in desorption efficiency.

3.7. Optimization of Static Desorption of $\varepsilon$-PL by Orthogonal Array Test. Orthogonal array test has been successfully used in the optimization of bioproduct extractions from fermentation broths and other plant materials [36-38]. In the present study, based on the single-factor analysis results, a $L_{9}\left(3^{3}\right)$ orthogonal array composed of 16 run, 4 factors, and 3 levels was used to optimize desorption conditions of $\varepsilon$ $\mathrm{PL}$ from resins. $\mathrm{HCl}$ concentration $(A)$, desorption time $(B)$, 
TABLE 3: Factors and levels in $L_{9}\left(3^{3}\right)$ orthogonal array and desorption efficiencies in different media.

\begin{tabular}{lccccc}
\hline \multirow{2}{*}{ Run } & \multicolumn{3}{c}{ Factor and level } & \multicolumn{2}{c}{ Desorption rate (\%) } \\
& $A$ & $B$ & $C$ & HZD-3B & D155 \\
\hline 1 & 1 & 1 & 1 & $74.61 \pm 0.55$ & $64.18 \pm 1.19$ \\
2 & 1 & 2 & 2 & $75.03 \pm 0.26$ & $64.84 \pm 0.92$ \\
3 & 1 & 3 & 3 & $76.15 \pm 1.02$ & $67.17 \pm 1.02$ \\
4 & 2 & 1 & 2 & $86.17 \pm 1.01$ & $87.09 \pm 1.69$ \\
5 & 2 & 2 & 3 & $87.74 \pm 1.61$ & $87.99 \pm 0.99$ \\
6 & 2 & 3 & 1 & $86.11 \pm 1.12$ & $85.74 \pm 0.35$ \\
7 & 3 & 1 & 3 & $85.13 \pm 0.41$ & $96.81 \pm 0.19$ \\
8 & 3 & 2 & 1 & $82.74 \pm 1.27$ & $93.35 \pm 1.06$ \\
9 & 3 & 3 & 2 & $84.37 \pm 1.87$ & $96.34 \pm 0.08$ \\
\hline
\end{tabular}

TABLE 4: The analysis of orthogonal extremum. $k_{1}, k_{2}$, and $k_{3}$ are the average values of three levels. $R$ is the deference between extremums.

\begin{tabular}{lcccccc}
\hline Level & \multicolumn{3}{c}{ HZD-3B } & \multicolumn{3}{c}{ D155 } \\
\hline$k_{1}$ & 75.26 & 81.97 & 81.15 & 65.40 & 82.69 & 81.09 \\
$k_{2}$ & 86.67 & 81.84 & 81.86 & 86.94 & 82.06 & 82.76 \\
$k_{3}$ & 84.08 & 82.21 & 83.01 & 95.50 & 83.08 & 83.99 \\
$R$ & 11.41 & 0.37 & 1.86 & 30.10 & 1.02 & 2.9 \\
Optimum level & $A_{2}$ & $B_{1}$ & $C_{3}$ & $A_{3}$ & $B_{3}$ & $C_{3}$ \\
\hline Significant order & \multicolumn{3}{c}{$A>C>B$} & \multicolumn{3}{c}{$A>C>B$} \\
\hline
\end{tabular}

and desorption temperature $(C)$ were used as the processing factors and desorption rate of $\varepsilon$-PL was used as the evaluation indicator (Table 3).

The influences of the processing variables on the indicators were determined using range $(R)$ analysis (Table 4 ) and ANOVA (Table S3). The statistical significances of the effects of the factors on the $\varepsilon$-PL desorption from both HZD-3B and D155 resins were in the order of $A$ (HCL concentration) $>C$ (adsorption temperature $)>B$ (adsorption time). Ftest was then used to determine, at a specific confidence level, whether these factors had significant effects on the $\varepsilon$-PL desorption efficiency of resins. Higher $F$-values indicate more significant effects of the factors. The $F$-test of the variances of the orthogonal array showed that the only factors $A(\mathrm{HCl}$ concentration) and $C$ (desorption temperature) were significant $(p<0.05)$ for $\varepsilon$-PL desorption efficiency (Table S3) and factor $B$ (desorption time) was insignificant $(p>0.05)$ for the $\varepsilon$-PL desorption efficiency. The $\varepsilon$-PL desorption conditions for HZD-3B resin were optimized as $A_{2} B_{1} C_{3}$, for example, $0.4 \mathrm{~mol} / \mathrm{L} \mathrm{HCl}$, desorption time $8 \mathrm{~h}$ and desorption temperature $30^{\circ} \mathrm{C}$. The optimal $\varepsilon$-PL desorption conditions of D155 resin were determined as $A_{3} B_{3} C_{3}$, for example, $0.4 \mathrm{~mol} / \mathrm{L}$ $\mathrm{HCl}$, desorption time $10 \mathrm{~h}$, and desorption temperature $30^{\circ} \mathrm{C}$. Under the optimal conditions, the experimental $\varepsilon$-PL desorption efficiencies of HZD-3B and D155 resins were $87.98 \%$ and $97.57 \%$, respectively, indicating that the desorption conditions optimized by the orthogonal array test were reliable.

3.8. $\varepsilon$-PL Adsorption and Desorption Performances of HZD$3 B$ and D155 Resins. Table 5 shows the $\varepsilon$-PL adsorption and
TABLE 5: The static $\varepsilon$-PL adsorption capacity and elution ratios of HZD-3B and D155 resins.

\begin{tabular}{lcc}
\hline Resin & HZD-3B & D155 \\
\hline Adsorption amount (mg/g) & 260.51 & 258.24 \\
Adsorption rate (\%) & 97.69 & 96.84 \\
Desorption rate (\%) & 87.98 & 97.57 \\
The total recovery rate (\%) & 85.95 & 94.49 \\
\hline
\end{tabular}

desorption performances of HZD-3B and D155 resins. Both HZD-3B and D155 resins showed good adsorption capacities with $\varepsilon$-PL adsorption efficiencies of $97.69 \%$ and $96.84 \%$, respectively. Their desorption efficiencies were $87.98 \%$ and $97.57 \%$, respectively, under the optimal conditions, which, respectively, resulted in $85.95 \%$ and $94.49 \% \varepsilon$-PL recoveries. As can be seen, D155 resin is a better option for $\varepsilon$-PL extraction and purification. D155 resin is a macroporous weak acid resin made with a novel polymeric material containing a functional group (-COOH) [39]. The proton can exchange with a cation, and the oxygen atom can coordinate directly with cations, which results in the high sorption capacity, easy regeneration, and convenient operation of the resin [39]. In all, D155 resin is an effective resin for $\varepsilon$-PL sorption of.

\section{Conclusion}

Among the five test resins, HZD-3B and D155 resins showed better adsorption performances. The $\varepsilon$-PL adsorption conditions of HZD-3B resin were optimized as initial $\varepsilon$-PL concentration $40 \mathrm{~g} / \mathrm{L}, \mathrm{pH} 8.5$, resin dosage $15 \mathrm{~g} / \mathrm{L}$, and adsorption time $13 \mathrm{~h}$. The maximum $\varepsilon$-PL adsorption efficiency was $97.69 \%$ under the optimal condition. The $\varepsilon$-PL adsorption conditions of D155 resin were optimized as initial $\varepsilon$-PL concentration $40 \mathrm{~g} / \mathrm{L}, \mathrm{pH}$ of 8.5 , resin dosage $15 \mathrm{~g} / \mathrm{L}$, and adsorption time $14 \mathrm{~h}$. The maximum $\varepsilon$-PL adsorption efficiency was $96.84 \%$ under the optimal condition.

HZD-3B and D155 resins showed the similar variation tendency in ultrastructural surface and infrared spectroscopy before and after the $\varepsilon$-PL adsorption.

The $\varepsilon$-PL desorption conditions of HZD-3B resin were optimized as $0.4 \mathrm{~mol} / \mathrm{L} \mathrm{HCl}$, desorption time $8 \mathrm{~h}$ and desorption temperature $30^{\circ} \mathrm{C}$, which resulted in a $\varepsilon$-PL desorption efficiency of $87.98 \%$. Similar desorption conditions were optimized for D155 resin except a longer desorption time of $10 \mathrm{~h}$. The $\varepsilon$-PL desorption efficiency under the optimal conditions was $97.57 \%$. D155 resin gave higher $\varepsilon$-PL recovery, indicating it is a better ion exchange resin for $\varepsilon$-PL extraction.

\section{Abbreviations}

$\varepsilon$-PL: $\varepsilon$-Polylysine.

\section{Competing Interests}

The authors declare that they have no competing interests. 


\section{Acknowledgments}

The authors would like to gratefully and sincerely thank the research grants funded by Jiangsu Yiming Biological Co. Ltd., The Scientific, The National Natural Science Foundation of China (no. 21206177), and Jiangsu Province Social Development Foundation of China (SBE2015730013).

\section{References}

[1] Y.-T. Ho, S. Ishizaki, and M. Tanaka, "Improving emulsifying activity of $\varepsilon$-polylysine by conjugation with dextran through the Maillard reaction," Food Chemistry, vol. 68, no. 4, pp. 449-455, 2000.

[2] A. H. Chheda and M. R. Vernekar, "Improved production of natural food preservative $\varepsilon$-poly-l-lysine using a novel producer Bacillus cereus," Food Bioscience, vol. 7, pp. 56-63, 2014.

[3] L. Y. Cai, A. L. Cao, F. L. Bai, and J. R. Li, "Effect of $\varepsilon$ polylysine in combination with alginate coating treatment on physicochemical and microbial characteristics of Japanese sea bass (Lateolabrax japonicas) during refrigerated storage," LWT_Food Science and Technology, vol. 62, no. 2, pp. 10531059, 2015.

[4] J. Hiraki, T. Ichikawa, S.-I. Ninomiya et al., "Use of ADME studies to confirm the safety of $\varepsilon$-polylysine as a preservative in food," Regulatory Toxicology and Pharmacology, vol. 37, no. 2, pp. 328-340, 2003.

[5] S. Shima, H. Matsuoka, T. Iwamoto, and H. Sakai, "Antimicrobial action of $\varepsilon$-poly-L-lysine," The Journal of Antibiotics, vol. 37, no. 11, pp. 1449-1455, 1984.

[6] S. Jia, C. Xu, Z. Tan et al., "Isolation and characterization of a new epsilon-poly-L-lysine-producing strain TUST-2," Acta Microbiologica Sinica, vol. 50, no. 2, pp. 191-196, 2010.

[7] H. Y. Zhu, H. Xu, Q. Wu, and W. W. Chen, "Screening and identification of $\varepsilon$-PL producing strain," Microbiology China, vol. 32, no. 5, pp. 127-130, 2005.

[8] S. Duan and W. Zhu, "Isolating of a $\varepsilon$-polylysine-producing strain," Food and Fermentation Industries, vol. 33, no. 8, pp. 1417, 2007.

[9] A. K. Pandey and A. Kumar, "Improved microbial biosynthesis strategies and multifarious applications of the natural biopolymer epsilon-poly-l-lysine," Process Biochemistry, vol. 49, no. 3, pp. 496-505, 2014.

[10] L. M. Zhang, R. Li, F. Dong, A. Y. Tian, Z. J. Li, and Y. J. Dai, "Physical, mechanical and antimicrobial properties of starch films incorporated with $\varepsilon$-poly-L-lysine," Food Chemistry, vol. 166, pp. 107-114, 2015.

[11] S. Jia, C. Xu, and Z. Tan, "Isolation and characterization of a new e-poly-L-lysine -producing strain TUST-2," Acta Microbiologica Sinica, vol. 38, no. 2, pp. 191-196, 2010.

[12] S. C. Shukla, A. Singh, A. K. Pandey, and A. Mishra, "Review on production and medical applications of eopen-polylysine," Biochemical Engineering Journal, vol. 65, pp. 70-81, 2012.

[13] C. Xiong, Y. Li, G. Wang et al., "Selective removal of $\mathrm{Hg}(\mathrm{II})$ with polyacrylonitrile-2-amino-1,3,4-thiadiazole chelating resin: batch and column study," Chemical Engineering Journal, vol. 259, no. 1, pp. 257-265, 2015.

[14] C. H. Xiong, Y. Q. Zheng, Y. J. Feng et al., "Preparation of a novel chloromethylated polystyrene-2-amino-1,3,4-thiadiazole chelating resin and its adsorption properties and mechanism for separation and recovery of $\mathrm{Pt}(\mathrm{IV})$ from aqueous solutions,"
Journal of Materials Chemistry A, vol. 2, no. 15, pp. 5379-5386, 2014.

[15] A. A. Abdelgadir, L. Boudesocque-Delaye, I. Thery-Koné, A. Gueiffier, E. M. Ahmed, and C. Enguehard-Gueiffier, "Onestep preparative isolation of aristolochic acids by strong ionexchange centrifugal partition chromatography," Separation and Purification Technology, vol. 156, no. 17, pp. 444-449, 2015.

[16] R. S. Gilbert, G. G. Gonzalez, L. Hawel III, and C. V. Byus, "An ion-exchange chromatography procedure for the isolation and concentration of basic amino acids and polyamines from complex biological samples prior to high-performance liquid chromatography," Analytical Biochemistry, vol. 199, no. 1, pp. 86-92, 1991.

[17] H. Zong, Y. Zhan, X. Wu, A. Ru-han, and F. Q. Feng, "Ion exchange resin separation and purification of $\varepsilon$-poly-lysinefrom the fermentation broth of streptomyces violaceusniger," Journal of Food Science, vol. 32, no. 1, pp. 138-141, 2011.

[18] R. F. Itzhaki, "Colorimetric method for estimating polylysine and polyarginine," Journal of Analytical Biochemistry, vol. 50, no. 2, pp. 569-574, 1972.

[19] A. Lyddiatt, "Process chromatography: current constraints and future options for the adsorptive recovery of bioproducts," Current Opinion in Biotechnology, vol. 13, no. 2, pp. 95-103, 2002.

[20] J. Hiraki, M. Hatakeyama, H. Morita, and Y. Izumi, "Improved $\xi$-poly-L-lysine production of an S-(2-aminoethyl)-L-cysteine resistant mutant of Streptomyces albulus," Seibutsu-Kogaku Kaishi, vol. 76, no. 12, pp. 487-493, 1998.

[21] T. Yoshida and T. Nagasawa, " $\varepsilon$-poly-L-lysine: microbial production, biodegradation and application potential," Applied Microbiology and Biotechnology, vol. 62, no. 1, pp. 21-26, 2003.

[22] K. G. Zinoviadou, K. P. Koutsoumanis, and C. G. Biliaderis, "Physical and thermo-mechanical properties of whey protein isolate films containing antimicrobials, and their effect against spoilage flora of fresh beef," Food Hydrocolloids, vol. 24, no. 1, pp. 49-59, 2010.

[23] A. T. Cao and S. R. Xiao, "Structure and application of polylysine," China Brewing, vol. 188, no. 11, pp. 11-14, 2008.

[24] M. Iwata, M. S. Jami, and M. Sato, "Analysis of constant-current electro-osmotic dewatering of various solid-liquid systems by considering the creep deformation," Separation and Purification Technology, vol. 58, no. 2, pp. 274-281, 2007.

[25] P. Kahar, T. Iwata, J. Hiraki, E. Y. Park, and M. Okabe, "Enhancement of $\varepsilon$-polylysine production by Streptomyces albulus strain 410 using $\mathrm{pH}$ control," Journal of Bioscience and Bioengineering, vol. 91, no. 2, pp. 190-194, 2001.

[26] H. T. Zhang, Y. Li, J. Ou, and W. Q. Wu, "Resin Screening for the Isolation of $\varepsilon$-polylysine from fermentation broth," Journal of Chemical Research Applications, vol. 20, no. 1, pp. 108-112, 2008.

[27] H. T. Zhang, Y. Li, J. Ou, and W. Q. Wu, "Screening of resins available for separating $\varepsilon$-polylysine from ferment broth," Chemical Research and Application, vol. 20, no. 1, pp. 108-112, 2008.

[28] I. Ghodbane and O. Hamdaoui, "Removal of mercury(II) from aqueous media using eucalyptus bark: kinetic and equilibrium studies," Journal of Hazardous Materials, vol. 160, no. 2-3, pp. 301-309, 2008.

[29] W. Luo, H. Chen, L. M. Fan et al., "Adsorption behavior of Ltryptophan on ion exchange resin," Korean Journal of Chemical Engineering, vol. 28, no. 5, pp. 1272-1279, 2011.

[30] A. A. Hekmatzadeh, A. Karimi-Jashni, N. Talebbeydokhti, and B. Kløve, "Adsorption kinetics of nitrate ions on ion exchange resin," Desalination, vol. 326, no. 10, pp. 125-134, 2013. 
[31] K. H. Chu and M. A. Hashim, "Protein adsorption on ion exchange resin: estimation of equilibrium isotherm parameters from batch kinetic data," Biotechnology and Bioprocess Engineering, vol. 11, no. 1, pp. 61-66, 2006.

[32] M. Z. Alam, M. F. Mansor, and K. C. A. Jalal, "Optimization of decolorization of methylene blue by lignin peroxidase enzyme produced from sewage sludge with Phanerocheate chrysosporium," Journal of Hazardous Materials, vol. 162, no. 2-3, pp. 708715, 2009.

[33] P. Gupta and P. Parkhey, "A two-step process for efficient enzymatic saccharification of rice straw," Bioresource Technology, vol. 173, pp. 207-215, 2015.

[34] S. Tahmouzi, "Optimization of polysaccharides from Zagros oak leaf using RSM: antioxidant and antimicrobial activities," Carbohydrate Polymers, vol. 106, no. 1, pp. 238-246, 2014.

[35] V. A. Ivanov, V. I. Gorshkov, V. D. Timofeevskaja, and N. V. Drozdova, "Influence of temperature on ion-exchange equilibrium accompanied by complex formation in resins," Reactive and Functional Polymers, vol. 38, no. 2-3, pp. 205-218, 1998.

[36] Z. C. Zhang, Y. Li, and K. C. Zhang, "Application of statistical analysis for the optimization of mycelia and polysaccharide production by Tremella aurantialba," Food Technology and Biotechnology, vol. 45, no. 1, pp. 45-50, 2007.

[37] A. A. Patil, B. S. Sachin, P. S. Wakte, and D. B. Shinde, "Optimization of supercritical fluid extraction and HPLC identification of wedelolactone from Wedelia calendulacea by orthogonal array design," Journal of Advanced Research, vol. 5, no. 6, pp. 629-635, 2014.

[38] T. Wu, J. Yan, R. Liu, M. F. Marcone, H. A. Aisa, and R. Tsao, "Optimization of microwave-assisted extraction of phenolics from potato and its downstream waste using orthogonal array design," Food Chemistry, vol. 133, no. 4, pp. 1292-1298, 2012.

[39] C. H. Xiong, "Study on sorption of D155 resin for gadolinium," Journal of Rare Earths, vol. 26, no. 2, pp. 258-263, 2008. 

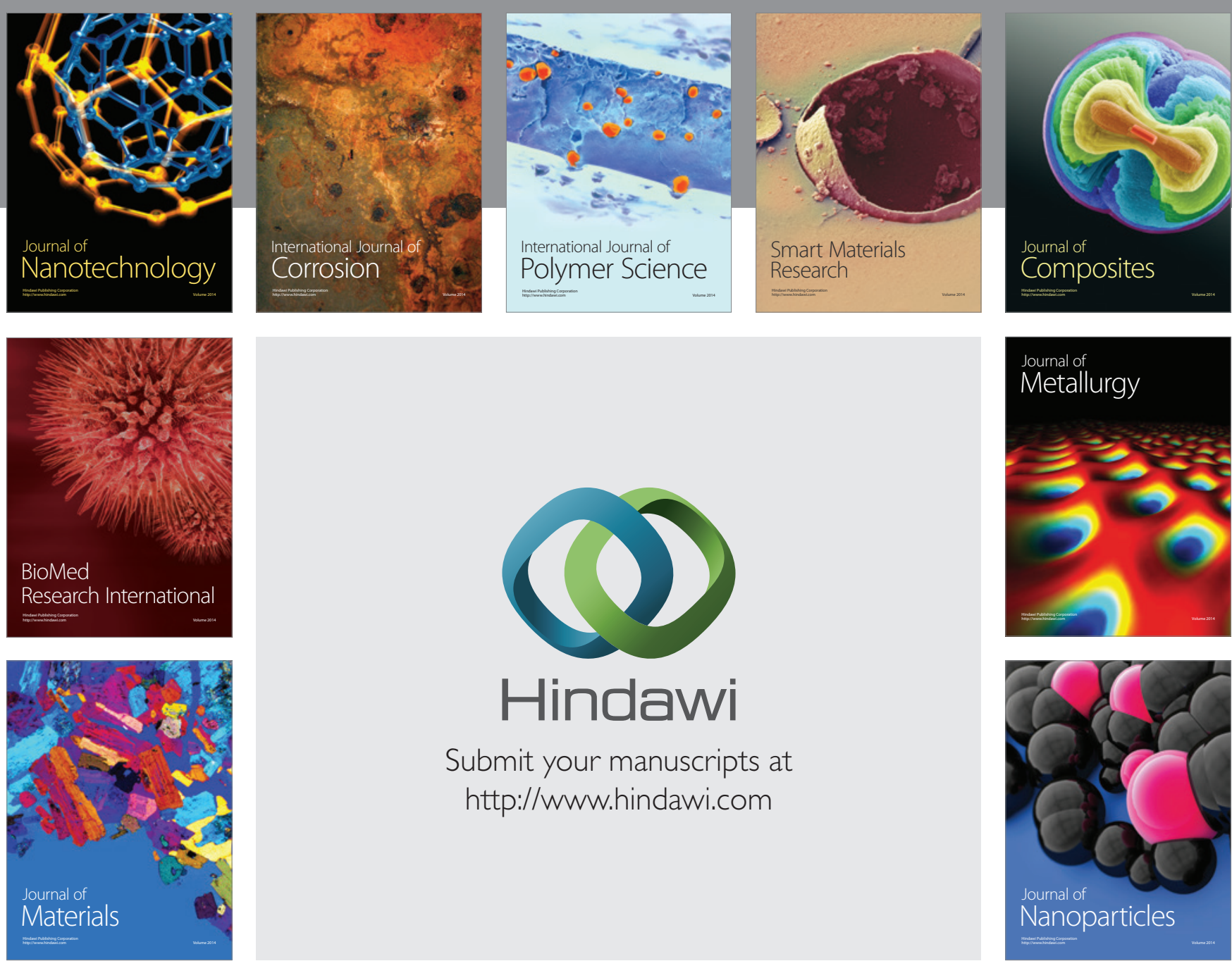

\section{Hindawi}

Submit your manuscripts at

http://www.hindawi.com

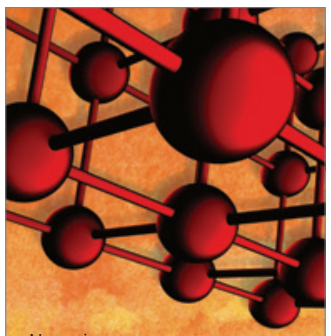

Materials Science and Engineering
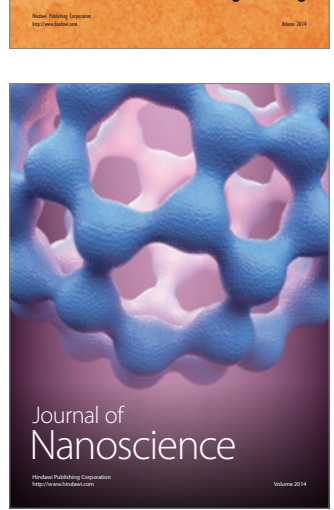
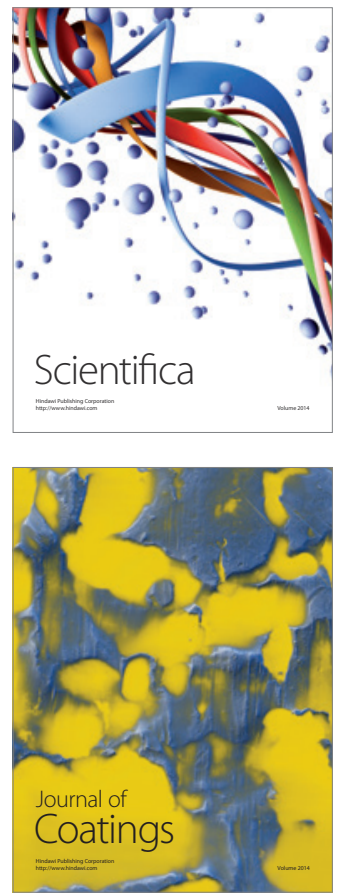
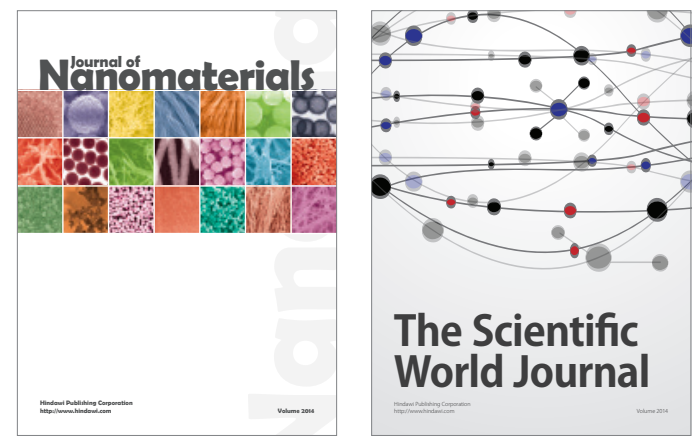

The Scientific World Journal
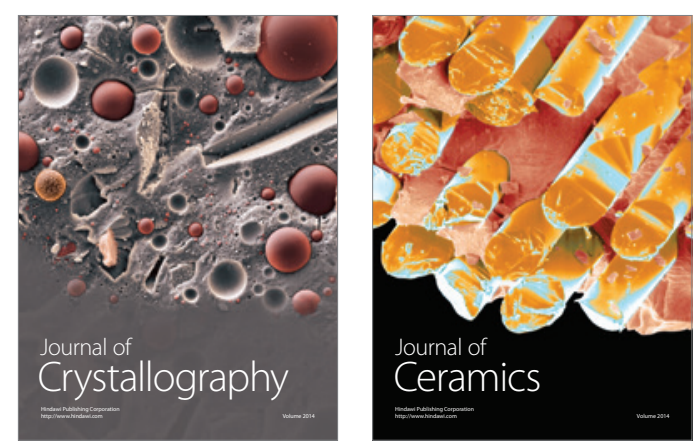
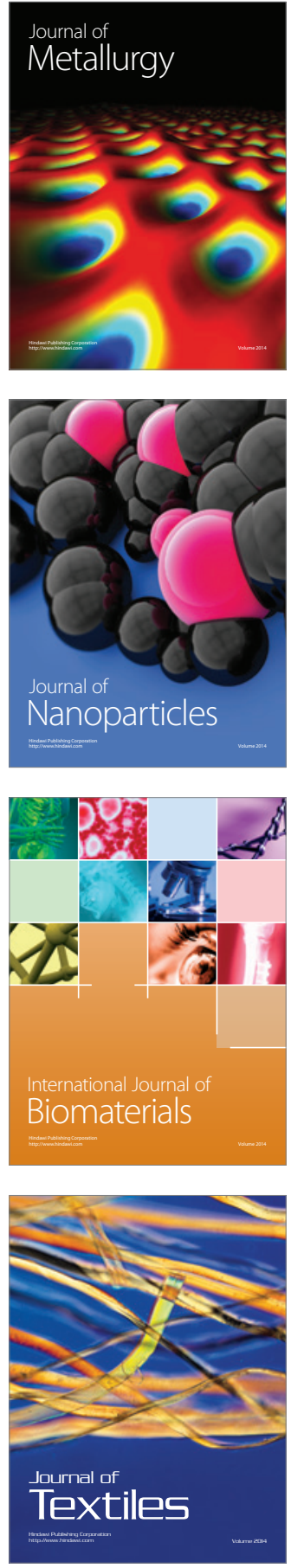